\title{
A FORMAÇÃO DE PROFESSORES PARA A GESTÃO ESCOLAR: DIVERSOS OLHARES
}

\author{
Deborah Breda da Silva ${ }^{1}$ \\ Silvana Neumann Martins ${ }^{2}$ \\ Aline Diesel ${ }^{3}$ \\ Natanael Pedro Castoldi ${ }^{4}$
}

\begin{abstract}
Resumo: A educação de qualidade é um desafio à escola e cabe à gestão escolar unir e conduzir os diferentes pensamentos a fim garantir a melhoria do ensino e da aprendizagem. Entretanto, por diversas vezes, o professor assume um cargo de gestão, sem ter uma formação específica, ignorando a complexidade da tarefa de gerenciar os espaços escolares. Diante dessa situação, objetivou-se investigar as percepçôes de gestores com relação aos desafios da gestão e as contribuições da formação inicial e da formação continuada na sua atuação. A formação inicial oferece ao professor o aporte teórico para a atuação docente, enquanto a formação continuada mostrou-se como ferramenta propulsora de desacomodação. A formação inicial forneceu as percepçôes teóricas em relação à gestão, porém, na prática, os profissionais encontraram dificuldades para lidar com os desafios desta carreira.
\end{abstract}

Palavras-chave: Gestão escolar. Desafios. Formação inicial. Formação continuada. Professores.

\section{TEACHER TRAINING FOR SCHOOL MANAGEMENT: SEVERAL PERCEPTIONS}

\begin{abstract}
Quality education is a challenge to the school and it is up to the school management to unite and lead the different thoughts in order to a common goal: improvement of teaching and learning. On several occasions the teacher assumes a management position without specific training,
\end{abstract}

1 Estudante de Nutrição. Bolsista de Iniciação Científica (Fapergs). Univates. E-mail: deborah.silva@universo.univates.br

2 Doutora em Educação. Docente do Programa de Pós-Graduação em Ensino e do Programa de Pós-Graduação em Ensino de Ciências Exatas. Univates. E-mail: smartins@univates.br

3 Mestre em Ensino. Docente da Educação Básica. E-mail: aline.diesel@hotmail.com

4 Estudante de Psicologia. Bolsista de Iniciação Científica. Univates. E-mail: natanaelcastoldi@gmail.com 
ignoring the complexity of the assignments of school managing. The purpose of this study is to investigate managers perceptions regarding management challenges and the contributions of initial training and continuing training in their work. The initial training offers the teacher the theoretical contribution to the teaching acting, while continuing education has proved to be a propelling tool for dismantling. Initial training provided the theoretical insights regarding management, but in practice, the teachers managers encountered difficulties in coping with the challenges of this career.

Keywords: School Management. Challenges. Initial formation. Continuing Education. Teachers.

\section{INTRODUÇÃO}

Vivemos em uma sociedade que está sofrendo mudanças profundas e cada vez mais velozes, nas mais diversas esferas. A escola, por sua vez, deve manter-se atenta e acompanhar todo esse dinamismo. Trata-se de um grande desafio para a qualidade da educação, que se torna ainda mais complexa pelo fato de a escola ser constituída por indivíduos diversos, com olhares diferentes, que tiveram formações diferentes, e que são oriundos de contextos distintos.

Nesse sentido, cabe à gestão escolar agregar todos esses sujeitos, conduzindoos a trabalharem para um mesmo objetivo, que é a qualidade na educação. Para tanto, a gestão escolar tem como principal objetivo identificar os problemas atuais da instituição de ensino e, através de debates com toda a equipe envolvida nos processos escolares, desenvolver um plano de ação com propostas e objetivos a serem atingidos, visando à melhoria do ensino e da aprendizagem.

Cabe destacar que o conceito de gestão trabalhado neste estudo não está vinculado à área financeira/administrativa de empresas, mas sim à escola. Ao contrário do gestor de empresas, que, provavelmente, teve toda uma formação acadêmica de embasamento, o cargo de gestor de escola é ocupado, normalmente, por um professor que, na maioria das vezes, não teve uma formação específica na área administrativa.

Tal circunstância motivou a realização do presente trabalho, que se propôs a refletir acerca da formação de professores para a atuação na área da gestão escolar. Dessa forma, delimita-se como objetivo investigar as percepções de gestores com relação aos desafios da gestão e as contribuições da formação inicial e da formação continuada na atuação do gestor escolar.

Este estudo foi desenvolvido no âmbito do projeto de pesquisa Mestrados para a Formação de Docentes: um lócus de (re)construção e de aprendizagem, que tem como um de seus objetivos investigar os impactos dos Programas de Pós-Graduação e dos cursos de Licenciatura de uma Instituição de Ensino Superior (IES), localizada no Estado do Rio Grande do Sul/Brasil, no que se refere à gestão escolar, ao empreendedorismo e às metodologias ativas de ensino. Em virtude disso, foram definidos como sujeitos deste trabalho gestores que são egressos do Mestrado em Ensino da referida IES.

A fim de apresentar este trabalho, que traz os olhares dos autores deste artigo, dos teóricos pesquisados e dos sujeitos entrevistados sobre a formação 
de professores e a gestão escolar, cabe salientar que, após a apresentação e a contextualização, o que se tem feito na presente etapa, apresenta-se o aparato teórico. Posteriormente, são traçados os procedimentos metodológicos adotados, seguidos das análises das categorias e as considerações finais.

\section{APORTE TEÓRICO}

\subsection{A gestáo escolar}

O gestor escolar tem uma posição de destaque, uma vez que cabe a ele o papel de gerenciar todos os processos educacionais dentro do ambiente escolar, seja em relação aos recursos físicos, econômicos e sociais. Gerir uma escola é um processo evolutivo, descentralizado e participativo. Para conhecer como se dá esse percurso, importa aqui apresentar um breve histórico da gestão escolar no Brasil.

De acordo com Gonçalves (2015), a discussão acerca de gestão escolar ganhou maior relevância a partir dos anos 80 , devido ao momento histórico que o país se encontrava naquela época, isto é, o fim da Ditadura Militar (1964-1985). Nessa época, conforme o autor, intensificou-se a campanha de redemocratização do país e, com a Constituição Federal de 1988, surgiu uma nova perspectiva de democracia, inclusive no espaço escolar. Desde então, a gestão escolar tem se tornado cada mais dinâmica e abrangente, e, atualmente, deve estar vinculada a um projeto educativo, desenvolvido por todos os sujeitos que integram a comunidade escolar (GONÇALVES, 2015).

A origem etimológica da palavra gestão, segundo Curry (2002), significa carregar, executar e gerar algo que implica o sujeito. Isto é, o gestor é responsável por liderar a escola, assumir a frente, buscar oportunidades para superar os desafios. Ao profissional da educação responsável pela gestão escolar compete o planejamento, a orientação, a organização, a liderança, a mediação, o monitoramento e a avaliação dos resultados alcançados (LÜCK, 2009).

Lück (2013) segue afirmando que a gestão escolar é uma área que determina a dinâmica e a qualidade do ensino, o que se explica pelo fato de a gestão ser responsável pela unidade, direcionamento, consistência e coerência das ações educacionais. Esses aspectos estão voltados para a melhoria do ensino e da aprendizagem. Sem essa melhora, a gestão se desqualifica e perde sua razão. De modo geral, a gestão deve ser focada em melhoria de aprendizagem e formação de alunos, portanto, uma boa gestão é facilmente identificada pelos seus resultados (LÜCK, 2013).

Nesse mesmo sentido, Gracindo (2012) propõe que gestão escolar está diretamente relacionada com o processo evolutivo da educação, considerando todos os indivíduos envolvidos em suas ações. Isto é, a gestão é o meio pelo qual todos participam do processo educativo, objetivando a construção de um plano de ação efetivo. Como principais aspectos da gestão podem ser citados: participação, autonomia, transparência e pluralismo (ARAÚJO, 2000). 
Para Dalcorso e Allan (2011), o gestor deve ser capaz de dividir funções, isto é, descentralizar o 'poder', o que envolve compartilhar as responsabilidades, tornando o trabalho mais efetivo e proveitoso. É importante, também, que esse gestor seja ativo e curioso, que busque referenciais teóricos para ter embasamento para enfrentar os diversos desafios propostos pela gestão. Nessa linha, Lück (2009) propõe como outra característica fundamental do gestor o espírito de liderança, sabendo como organizar e motivar sua equipe. O líder deve ser capaz de gerenciar o grupo de pessoas envolvido nos processos de ensino e de aprendizagem, visando alcançar resultados positivos, conforme objetivos comuns (ROMANO; DE OLIVEIRA, 2016).

Lück et al. (2011) também evidenciam que o responsável pela gestão escolar não é somente o próprio gestor, e sim toda a equipe escolar, ou seja, envolve além dos professores e funcionários, os alunos e membros da comunidade escolar. A opinião de todos e suas contribuições são fundamentais para a melhoria das questões pedagógicas. Portanto, a gestão é um processo de identificação dos problemas escolares e, através de debates planejar um conjunto de ações que busquem a solução desses desafios encontrados. Nota-se que gerenciar todas essas questões é instigante, devido à complexidade de transformar propostas em ações (SOUZA, 2009).

Diante disso, nota-se que a gestão escolar é um desafio especialmente porque está relacionada com decisões que devem ser tomadas, e o que tem que ser feito nem sempre contenta a todos, muito pelo contrário, pode ferir conveniências, desfazer o que está cômodo, ir além do que está sendo feito. A mudança de paradigmas nunca é simples, podendo haver resistência uma vez que está se trabalhando com pessoas. Por isso, o trabalho do gestor deve estar sempre associado com diálogo, negociação e interação com o outro, reafirmando a ideia de que todo gestor deve ser um líder (VIEIRA, 2014).

A Constituição Federal de 1988, Art. 206, Inciso VI, destaca os princípios da gestão no ensino, sendo eles: I. Participação dos profissionais da educação na elaboração do projeto pedagógico da escola; II. Participação da comunidade escolar e local em conselhos escolares ou equivalentes (BRASIL, 1988). Tais princípios representam que, para uma gestão efetiva, é preciso que haja também autonomia e participação de todos os envolvidos no ambiente escolar, além do próprio gestor. Sem esses princípios, a gestão escolar não evolui e não se concretiza.

Gonçalves (2015) reforça esse pensamento. De acordo com o autor, é preciso promover uma união da comunidade escolar para que haja participação efetiva de todos. É preciso que a comunidade esteja consciente de que a união faz sua força aumentar. Dessa forma, conforme o referido autor, professores, pais, alunos e demais funcionários se afirmam também como gestores e assumem sua parte de responsabilidade pelo projeto da escola.

A escola ensina e aprende ao mesmo tempo. Além disso, nesse espaço há sempre troca de ideias e valores. Contudo, ainda se nota que a organização escolar é pesada e prudente: pesada por ter burocratizado demais os processos de gestão e 
assim, por mais que se aumente os programas de capacitação, a sensação é de que a mudança praticamente inexiste; e prudente porque precisa considerar antes de qualquer ação seu passado, presente e preparar o futuro (MORAN, 2009).

De acordo com o autor, "bons professores são as peças-chave na mudança educacional. [...] A educação não evolui com professores mal preparados" (MORAN, 2009, p. 18). Diante disso, deve-se pensar sobre os tipos de formação que estão tendo esses professores e, a partir dá, iniciar as mudanças. Nesse sentido, esse estudo considera as formações inicial e continuada dos professores acerca da gestão escolar, e como estas formações influenciaram suas práticas gestoras.

\subsection{A formaçáo inicial e continuada do gestor escolar}

Em relação à formação inicial de professores, Santos (2008) aponta que esta é responsável pelo começo da socialização profissional e por fornecer as bases do pensamento pedagógico. Logo, o que se espera dessa primeira formação é que ela seja capaz de criar processos reflexivos sobre teoria e realidade da atuação do professor.

Considerando a complexidade do trabalho do gestor, a formação inicial sozinha não é capaz de garantir ao professor todo o aperfeiçoamento para a carreira de gestor. Assim, a formação continuada tem grande importância em tal contexto. Nesse sentido, Freitas (2004, p. 91) aponta: "A formação continuada, articulada à formação inicial e às condições de trabalho, salário e carreira, é uma das dimensões importantes para a materialização de uma política global para a formação e valorização do profissional da educação".

De acordo com Nóvoa (2012), deve-se entender o ensino como criação, e não pela transmissão de conhecimentos pré-existentes. Tal criação baseia-se em modelos já existentes, porém elabora um conhecimento novo que faça sentido ao aluno. Para tanto, criar não é tarefa simples, não é simplesmente aplicar uma teoria, exige esforço e reelaboração do professor que são concebidos através de novos modelos de formação inicial e continuada de docentes (NÓVOA, 2012).

Diante dessas considerações, destaca-se a importância de pensar nos processos de formação do gestor, e como essa formação irá influenciar as suas práticas. Essa aquisição de conhecimentos é fundamental e necessária, considerando a realidade da gestão escolar no Brasil. Dados do MEC (2009) demonstraram que 29,32\% dos gestores escolares possuem apenas formação em nível médio, 69,79\% possuem formação em nível superior, porém destes somente $22,96 \%$ possuem algum curso de pós-graduação. Em vista desses dados, problematizam-se os programas e os projetos de formação de gestores (MELO, 2013).

Segundo Moran (2009, p. 25), "uma boa escola começa com um bom gestor", isto é, o gestor tem papel crucial na organização da escola, em torná-la mais dinâmica e motivadora. E este é um dos principais papéis do gestor: inspirar. Inspirar seus funcionários e alunos, inspirar comunidade e os pais, e por fim, articular tudo isso. Assim, seus saberes são articulados e o ensino se torna mais 
efetivo. É essencial que o gestor saiba olhar para as dificuldades e enxergá-las como oportunidades.

\section{METODOLOGIA}

Com o propósito de atender o objetivo deste trabalho, que segue uma abordagem qualitativa, foram realizadas entrevistas semiestruturadas com seis professores, egressos do Mestrado em Ensino, o qual é oferecido por uma instituição de ensino superior localizada no Rio Grande do Sul. Esses professores ocupam cargos de gestão em suas instituições de ensino.

Num primeiro momento, foi realizado uma revisão bibliográfica acerca dos conceitos sobre gestão no ensino, formação inicial de professores e formação continuada. Com base nesse estudo, foi elaborado o roteiro da entrevista e, após, realizaram-se as entrevistas, a fim de verificar em que medida o Mestrado em Ensino contribuiu na atuação gestora dos mestres. O conteúdo das entrevistas foi gravado pelos pesquisadores e, após, transcrito, o que facilitou o tratamento dos dados coletados, que foram analisados à luz de pressupostos da técnica da Análise Textual Discursiva (MORAES, 2007). Essa técnica sugere a desconstrução dos textos e organização dos elementos em unidades de sentido e ou significado.

Salientamos, ainda, que os professores preencheram o Termo de Consentimento Livre e Esclarecido (TCLE), no qual autorizaram a publicação das informações para fins educacionais. Entretanto, para preservar a identidade dos sujeitos, optamos por denominá-los, aqui, por M1, M2, e assim sucessivamente, até M6.

\section{ANÁLISE E DISCUSSÃO}

A partir das falas coletadas com os entrevistados, definiram-se as seguintes unidades de sentido, que convergem com o objetivo do trabalho: concepção de gestão, desafios da gestão escolar, contribuição da formação inicial para o gestor escolar e contribuição da formação continuada para o gestor escolar.

\subsection{Concepçáo de gestáo}

Em relação às concepções de gestão, os entrevistados apontaram o seguinte:

M1: “Questão da liderança, que a gente não pode ser um líder sozinho, a gente tem que na verdade saber também dividir, não querer abraçar o mundo sozinho, dividir as coisas e não só que pode permitir sim que alguém te mande fazer uma coisa, não achar que só tu tem que mandar, dividir as tarefas. "

Nessa colocação, o entrevistado chama a atenção para o fato de o gestor ter de saber compartilhar responsabilidades. Essa ideia converge com a perspectiva de Lück (2009), que afirma que o professor que assumir um cargo que envolva liderança deve dedicar-se ao estudo, à observação e à reflexão sobre essa liderança, a fim de exercê-la de forma adequada. Em outros termos, gestão significa liderar 
em prol do bem comum, não com autoridade, mas com respeito da equipe de trabalho.

Nessa mesma linha, seguem as falas transcritas a seguir:

M1: “[...] um bom diretor, uma boa gestora, deveria primeiramente aprender a escutar, e não a falar, deveríamos escutar mais e falar menos."

M3: “[...] mas a ideia que eu tenho é que tem que haver uma discussão uma troca de ideias, saber ouvir o outro né, entender o outro, é aquilo que a professora falava, o olhar atento, o ouvir ativo né, assim, isso muitas vezes não acontece, e isso também é numa sala de aula, né, com meu aluno né, em todas as situações que a gente for pensar, é escutar o outro, ver o que ele tem pra falar, e aí eu colocar a minha opinião, e daqui a pouco o outro também vai colocar de novo a sua, e a gente entrar em um consenso."

Com as falas dos professores gestores, podemos notar que, para eles, o conceito de gestão é bem claro. De acordo com a perspectiva dos entrevistados, gerir uma escola significa contar com a participação de todos os envolvidos no ambiente escolar, e principalmente, um bom gestor deve ter seu olhar ampliado, isto é, precisa enxergar além das suas próprias dificuldades, pois a efetividade da atuação do gestor será proporcional a sua concepção de organização escolar (SOUZA, 2006).

Cabe, também, transcrever o seguinte excerto:

M4: "Estar presente é o coletivo, é deixar o eu de lado, em primeiro lugar. Em segundo lugar, planejamento. E que esse planejamento seja também coletivo, um planejamento a longo prazo. Que esse planejamento tenha metas. Que haja um comprometimento com essas metas, que de vez enquanto se volte para essas metas, para que elas sejam relembradas.... E o planejamento, eu acho que é extremamente importante escutar todos, principalmente os colegas professores ou o aluno..."

Lück (2009) aponta como características fundamentais do gestor escolar: garantir o funcionamento e a organização escolar; aplicar e orientar ações que promovam a escola em todas as suas dimensões; promover ações voltadas para a aprendizagem e formação dos alunos; promover unidade e desenvolvimento equilibrado do trabalho de forma integrativa; mobilizar talentos e competências dos participantes da comunidade escolar para promoção da educação. Essas características vão ao encontro de todas as colocações dos entrevistados e, portanto, percebe-se que os profissionais possuem concepções harmonizadas do trabalho de gestor.

M3: "Quando muitas vezes se fala em gestão eles pensam logo lá na direção né, em alguém que está lá, mas eu não vejo isso, a gestão tem que ser de sala de aula, ou eu lá, com meu grupo lá na cozinha, né, as merendeiras da escola, elas também têm um grupo lá, tem que haver essas relações entre elas, conseguir conversar com outro, parece que falta isso hoje." 
M5: “..., pensar a gestão educacional não é tarefa simples, como nada é simples na educação né, tudo exige muito estudo, muito cuidado, muito planejamento também, [...] o planejamento do teu fazer, administrativo e pedagógico..."

A formação específica para gestão escolar aparece nas falas dos professores entrevistados, demonstrando que esta é uma necessidade real na formação de profissionais da educação com perfis diferenciados. Tal ideia é sustentada por Lück (2009), que diz que o profissional que assume esses cargos de gestão deve necessariamente se dedicar ao estudo, à observação e à reflexão, para que tenham condições de exercer gestão e a liderança de forma competente.

\subsection{Desafios da gestáo escolar}

Em relação aos desafios da prática de gestor escolar, os gestores entrevistados apontaram vários aspectos, como podemos ver nos seguintes excertos:

M1: "Lidar com os imprevistos é uma dificuldade que eu ainda tenho"

M3: “...é um desafio enorme, mas as relações entre as pessoas, às vezes por uma coisinha pequena, se faz um auê todo, que poderia ser tão facilmente resolvido né..."

M4: "Eu acho que ainda os principais desafios são em relação ao olhar que a gente ainda olha pra escola e não entende a escola como sendo, não é uma empresa, mas a gente tinha que ter um olhar de haver um comprometimento com resultados. A gente vai para a escola e meio que faz um trabalho e "vamos ver no que vai dar", "vai que dá certo". E uma empresa não pode ter esse olhar. "

M6: "Alguns professores [mais antigos] são mais resistentes. 'ah, agora já estou perto de me aposentar, agora eu não preciso mais aprender isso'."

Dentre os apontamentos, consideramos importante destacar a comparação entre uma empresa e uma escola. A escola, diferentemente de uma empresa, não visa fins lucrativos, contudo, busca resultados. Em uma empresa, quando os resultados não aparecem, as práticas são revistas a fim de encontrar onde está a falha que impede que os resultados melhorem, e é esse pensamento que os professores devem levar para a escola. É fundamental estabelecer comprometimento com resultados buscando atingir essas metas. Vale ainda destacar que por resultados não se entende aumentar a média de notas dos alunos, mas aumentar a qualidade do ensino dos professor e da aprendizagem dos alunos.

Entre os desafios apontados pelos sujeitos entrevistados, M1 mencionou os imprevistos que surgem ao longo da rotina escolar, que atrapalham o planejamento do gestor. Os entrevistados M3, M4 e M6 referem-se a aspectos da relação entre as pessoas envolvidas, tendo que resolver conflitos entre alunos, pais, professores, funcionários e outros envolvidos. Isso também vai ao encontro das falas de Lück (2009) que afirma que desenvolver a competência de gestor é um desafio contínuo assumido pelo profissional, e a escola será um reflexo de suas habilidades. 
Para De Carvalho, De Oliveira e De Lima (2014), essas características, como lidar com imprevistos, relações interpessoais, enfrentar desafios, ampliar o olhar entre outros, são os aspectos que caracterizam uma gestão comprometida e efetiva. Ainda para os autores, "a capacidade de adaptação às mudanças e à proatividade frente aos desafios" (2014, p. 60) são fundamentais para gerir com qualidade.

Para atingir os propósitos deste trabalho, cabe, ainda, apresentar as inquietações de M4:

M4: "E como lidar com isso? Como fazer a gestão disso tudo? Como administrar, numa sala de aula com 30 alunos, e desses 30 tem 5 que não querem desenvolver aquela proposta? E aí, como é que eu faço? E esse é o grande desafio das escolas, das universidades".

Essas provocações voltam-se para Curry (2002), segundo o qual o gestor está constantemente superando desafios através da busca de oportunidades, isto é, o gestor deve ser flexível em suas propostas em ações de forma a adaptá-las conforme as demandas que forem surgindo no ambiente escolar.

M5: "Esse tempo de crise e de desafios como algo negativo? Não é algo negativo, que em cima da crise, em cima do desafio, tu consegues ver possibilidades criadoras que tu consigas ver, visualizar possibilidades criadoras, quando tu cria um problema, ou vem a ti um problema que tu precisa resolver, naquele momento..."

M5: “...é um desafio, é um desafio constante, é um desafio diário, e que a gente tem que estar sempre buscando, reinventando outras possibilidades, de pensar esse contexto..."

Nota-se, portanto, que apesar de ser um desafio os profissionais enfrentam essas dificuldades como uma oportunidade de melhorar ainda mais o ambiente escolar. O profissional deve ser criativo e aberto a mudanças para lidar com as questões que aparecerão no decorrer da caminhada da gestão escolar.

\subsection{Contribuiçáo da formaçáo inicial para o gestor escolar}

Em relação à formação inicial de professores e sua influência na carreira de gestor, os professores entrevistados contribuíram com as falas a seguir:

M2: "Na graduação eu tinha uma visão muito do passar o conteúdo, porque é essa a formação em si, do passar o conteúdo, de cobrar esse conteúdo, e muito daquela questão de exigir para uma questão de vestibular [...] de passar o conteúdo específico."

Como apontou Santos (2008), a formação inicial é responsável por fornecer o embasamento pedagógico a fim de desenvolver neste profissional um pensamento reflexivo que considere a teoria e a prática dos processos de gestão.

Podemos observar nas falas dos entrevistados M3 e M6, transcritas a seguir, que os cursos de graduação/licenciatura contribuem com um aporte teórico relacionado à área de formação, excluindo, na maioria das vezes, os aspectos 
extrínsecos de ensinar, isto é, aquilo que vem do outro, o saber ouvir, contextualizar e conhecer seu aluno.

M3: "Específico a gente não teve a disciplina, mas sempre, muitas disciplinas os professores colocavam, essa questão se saber ouvir o outro, de tentar ver a realidade do aluno, contexto dele, então, específico não se tinham, mas se tinha que ela fala, e eu acho que muito veio com a experiência, e ao mesmo tempo tem que partir de ti, tu tem que estar aberta a procurar..."

M6: "Eu observo que alguns cursos ainda pecam muito na questão de empreendedorismo, estão muito mais preocupados em distribuir ali um conhecimento que deve ser reaplicado e não repensado para ser depois, como vou dizer, pra que ele possa na sala de aula ser, aplicado conforme a situações, conforme a própria busca pelas diferenças que existem na sala de aula".

Essas colocações convergem com o estudo de Pereira (2015), no qual foi averiguado que a dificuldade do estabelecimento das relações das práticas de gestão por professores está relacionada com a formação inicial dos mesmos, em que, na maioria das vezes, não ficam completamente esclarecidas as concepções da atuação do gestor.

\subsection{Contribuição da formaçáo continuada para o gestor escolar}

Além de preencher possíveis lacunas deixadas pela formação inicial, a formação continuada contribui de forma construtiva e evolutiva na carreira do profissional. Dessa forma, ela deve ser marcada pelo aprimoramento, aspiração de ganhar novos conhecimentos, de superar desafios e de empreender mudanças (DAVIS, 2013).

Em relação à formação continuada, evidenciaram-se as seguintes contribuições dos gestores entrevistados:

M4: "A importância da leitura para o professor, da leitura e da escrita. E, nesse sentido, eu acredito que todo o professor teria que obrigatoriamente ter mestrado..."

M4: "E eu acho que a minha formação continuada sim, influenciou muito para que eu tivesse um olhar diferente. E por isso que eu insisto naquela questão de que todo o professor deveria ter um mestrado, porque a partir de um mestrado, eu acho que o mestrado te dá uma maturidade, não diria profissional, mas uma maturidade de tu ter um conhecimento sobre o que os grandes autores defendem, de tu ter um conhecimento do que é a proposta em educação, de tu ter um conhecimento de ver a escola como fazendo parte de um sistema maior que envolve a comunidade em que ela está inserida, e até questões ambientais. E eu acho que o mestrado te abre, nesse sentido".

Nesses discursos, percebemos que a partir da formação continuada é possível que o professor se mantenha atualizado e aberto a novas propostas e ferramentas de ensino e de aprendizagem. O professor que se propõe a inovar e a se reinventar, consegue estimular e produzir conhecimento efetivo em seus alunos. É um processo que permite ganhos ao professor e ao aluno. 
Nóvoa (2012) defende que a formação de professores deve ser um processo contínuo e interno, isto é, vindo de dentro da profissão, o que reforça o papel e a capacidade do professor de tomada de decisões e ações. $O$ autor ressalta a complexidade dessa tarefa, o que justifica a necessidade emergente de continuar a capacitar-se.

Para potencializar a discussão acerca da contribuição da formação continuada, apresentamos o depoimento de M6.

M6: “Total diferença. [...] a minha visão de escola, de gestão, de grupo mudou completamente após o mestrado, e eu tento sempre contribuir com os meus colegas professores na nossa reunião semanal, formações continuadas, pra que eles possam também despertar um olhar diferente, para aqueles que querem né... muitas vezes eles querem ouvir mas nas suas práticas são mais resistentes, mas eu observo que alguns professores modificaram bastante a sua prática".

Como se pode ver, o entrevistado destaca que, após a realização do mestrado, sua visão de escola e de gestão mudou completamente. A formação continuada, portanto, é a ferramenta central para o desenvolvimento profissional do docente, sendo ela responsável por dar sentido e valor à atividade do gestor (DAVIS, 2013). Pode-se notar que, ao sai da sua zona de conforto em busca de mais conhecimento, o professor se torna desacomodado, isto é, ele está sempre motivado a continuar se especializando e atualizando suas práticas pedagógicas.

\section{CONSIDERAÇÓES FINAIS}

Por meio da análise das entrevistas, pôde-se averiguar as percepções de gestores com relação aos desafios da gestão e as contribuições da formação inicial e da formação continuada na atuação de gestor escolar.

Com o estudo, evidenciou-se que, apesar do tema gestão não ter sido trabalho de forma isolada nos cursos de formação inicial e continuada, os professores tinham a percepção das atribuições de gestores bem esclarecida, porém a prática é falha. Para os entrevistados, o gestor deve ser responsável por liderar, e que essa liderança precisa ser feita através da motivação de todos os envolvidos nos processos de gestão. De acordos com os sujeitos deste estudo, ao assumir um cargo de gestor, o profissional acaba adquirindo na prática as habilidades necessárias, tendo que dedicar-se ao estudo. O bom andamento do espaço escolar é reflexo de uma gestão organizada e de qualidade.

Contudo, desenvolver as habilidades de gestor é uma tarefa complexa e exige a superação de diversos desafios. Aqui, pôde-se perceber que os maiores desafios encontrados pelos gestores foram resolver os imprevistos, lidar com relações interpessoais e assumir a própria liderança. Sabe-se que enfrentar esses desafios é parte da competência de gestor, e que essas dificuldades devem ser vistas como oportunidades de mudança, objetivando a melhora da aprendizagem. 
A formação inicial mostrou-se eficiente na tarefa de transmissão de conteúdos, oferecendo um aporte teórico que, por vezes, é falho em estabelecer relações com a prática. De modo geral, a gestão não é trabalhada com os licenciandos, deixando lacunas para quem irá exercer essa função. Tal evidência demonstra a necessidade de rever os currículos dos cursos de licenciatura, a fim de evitar essas falhas, formando profissionais diferenciados que saibam gerir não só o ambiente escolar, mas que sejam capazes de gerir também sua própria atuação docente garantindo um bom andamento dos processos de ensino.

Quanto à formação continuada, esta demonstrou ser uma ferramenta de desacomodação. Ela permite que o professor reflita sobre suas práticas e busque aprimoramentos. Um grande diferencial da formação continuada é abrir um leque de oportunidades para atualização, amadurecimento e autonomia, pois permite que o professor veja as novas demandas de ensino e que busque metodologias para superá-las. Uma vez que causa essa "saída" da zona de conforto, ela permite que o professor se especialize em gestão, compreendendo todas as suas dimensões.

Por fim, percebe-se que a carreira docente deve estar sempre em contínuo aperfeiçoamento, a fim de acompanhar a dinâmica dos processos de ensino e de aprendizagem. Tais resultados contribuem para orientar eventuais propostas de reestruturação curricular e o aperfeiçoamento dos cursos de licenciatura e do Mestrado em Ensino da instituição foco deste estudo.

\section{REFERÊNCIAS}

ARAUJO, Adilson César. Gestão democrática da educação: a posição dos docentes. 2000. 220 f. Dissertação (mestrado) - Faculdade de Educação, Universidade de Brasília, Brasília, 2000.

BRASIL. Constituição da República Federativa. 1988. Disponível em: <http:// presrepublica.jusbrasil.com.br/legislacao/91972/constituicao-da-republica-federativa-dobrasil-1988\#art-206--inc-VI> Acesso em: 12 set 2016.

CURRY, Carlos R. J. Gestão Democrática da educação: exigências e desafios. Revista Brasileira de Política e Administração da Educação. Porto Alegre, v. 18, n.2 jul/dez, 2002.

DALCORSO, C. Z.; ALLAN, L. M. Programa de Liderança: Reflexões e práticas para promover a gestão escolar com foco na melhoria da aprendizagem dos alunos. São Paulo: Conselho Britânico/Instituto Crescer, 2011.

DAVIS, Claudia L. F. Formação continuada de professores: uma análise das modalidades e das práticas em estados e municípios brasileiros. Textos FCC, v. 34, p. 104, 2013.

DE CARVALHO, Cynthia Paes; DE OLIVEIRA, Ana Cristina Prado; DE LIMA, Maria de Fátima Magalhães. Avaliações externas: tensões e desafios para a gestão escolar. Estudos em Avaliação Educacional, v. 25, n. 59, p. 50-76, 2014. 
FREITAS, H, C, L. A Formação Continuada dos profissionais da Educação. Revista Retratos da Escola no Brasil. Brasilia: CNTE. 2004.

GONÇALVES, Ademir Nunes. Fundamentos da Gestão Escolar: história, bases e princípios. 2015. Disponível em: < http://repositorio.unicentro.br:8080/ handle/123456789/431> Acesso em: 12 set 2016.

GRACINDO, Regina Vinhaes. O gestor escolar e as demandas da gestão democrática: exigências, práticas, perfil e formação. Retratos da Escola, v. 3, n. 4, 2012.

LÜCK, Heloísa. Dimensões de gestão escolar e suas competências. Curitiba: Positivo, 2009.

LUCK, Heloísa; FREITAS, Kátia Siqueira de; GIRLING, Robert; KEITH, Sherry. A escola participativa. $4^{\mathrm{a}}$ ed. Editora Vozes. Petrópolis. 2011.

LÜCK, Heloísa. Avaliação e monitoramento do trabalho educacional. Editora Vozes Limitada, 2013.

MELO, Darci Barbosa Lira de. Formação do gestor escolar em cursos de pósgraduação: análise da experiência da Escola de Gestores da educação básica em Pernambuco. 2013. Tese (Doutorado) - Universidade Federal de Pernambuco, CE. Programa de Pós-graduação em Educação, 2013.

MORAN, José Manuel. A educação que desejamos: novos desafios e como chegar lá. 4. ed. Campinas: Papirus, 2009.

MORAES, Roque; DO CARMO GALIAZZI, Maria. Análise textual: discursiva. Editora Unijuí, 2007.

NÓVOA, Antônio. Devolver a formação de professores aos professores Cadernos de Pesquisa em Educação - PPGE/UFES 11 Vitória, ES. a. 9, v. 18, n. 35, p. 11-22, jan./ jun. 2012

PEREIRA, V. S. A gestão escolar democrática na formação inicial do professor: os conhecimentos construídos em licenciaturas da Universidade Federal do Rio Grande do Sul. 2015. 106 f. Dissertação (Mestrado) - UFRGS. Faculdade de Educação, Programa de Pós-Graduação em Educação, Porto Alegre, 2015.

ROMANO, Alessandro Segala; DE OLIVEIRA, Márcia Pacini. A Gestão Participativa e o Papel Da Liderança Do Diretor na Educação Profissional Técnica The Participatory Management and the Director's Leadership Role in Vocational Education Technique.

REVISTA InSIET, v. 2, n. 2, p. 60-72, 2016.

SANTOS, Antônio Roberto dos. LDB 9.394/96: Alguns passos na formação de professores no Brasil. In: GRANVILLE, Maria Antonia (Org). Teorias e práticas na formação de professores. Campinas: Papirus, 2 ed., 2008.

SOUZA, Ângelo Ricardo de. Perfil da gestão escolar no Brasil. Tese de Doutorado em Educação: História, Política, Sociedade. Pontifícia Universidade Católica de São Paulo, São Paulo, 2006. 302 p. 
SOUZA, Â. R. Explorando e construindo um conceito de gestão escolar democrática. Educação em Revista. v. 25, n.03, p.123-140, dez. 2009.

VIEIRA, Sofia Lerche. Políticas e gestão da educação básica: revisitando conceitos simples. Revista Brasileira de Política e Administração da Educação-Periódico científico editado pela ANPAE, v. 23, n. 1, 2014. 